\title{
Effect of $\alpha$-chlorohydrin on glucose metabolism by spermatozoa from the cauda epididymidis of the rhesus monkey (Macaca mulatta)
}

\author{
W. C. L. Ford and Anne Harrison \\ Department of Physiology and Biochemistry, The University, Whiteknights, \\ Reading RG6 $2 A J, U . K$.
}

\begin{abstract}
Summary. Spermatozoa from the cauda epididymidis of the rhesus monkey had metabolic properties similar to those published for ejaculated spermatozoa. The concentration of glycolytic intermediates was low until $2 \mathrm{mM}$-glucose was added; glucose 6-phosphate, fructose 1,6-bis-phosphate and the triose phosphates then increased but glycerate 3-phosphate did not. It was concluded that the activity of glyceraldehyde 3-phosphate dehydrogenase (EC 1.2.1.12) limited flux through the glycolytic pathway. The production of lactate and $\mathrm{CO}_{2}$ from glucose was strongly inhibited in the presence of 5 or $10 \mathrm{~mm}-\alpha$-chlorohydrin. The energy charge of the spermatozoa was low before and after $1 \mathrm{~h}$ incubation with $2 \mathrm{~mm}$-glucose $(0.5 \pm$ 0.05 and $0.05 \pm 0.06$ respectively) and the value after the incubation was decreased in the presence of 5 or $10 \mathrm{~mm}$ - $\alpha$-chlorohydrin $(0.17 \pm 0.05$ and $0.15 \pm 0.04$ respectively). $\alpha$-Chlorohydrin inhibited glycolysis at the glyceraldehyde 3 -phosphate dehydrogenase reaction.
\end{abstract}

\section{Introduction}

$\alpha$-Chlorohydrin (3-chloropropan-1,2-diol) produces reversible infertility in male animals of several species including the rhesus monkey (Kirton, Ericsson, Ray \& Forbes, 1970; Setty, Kar, Roy \& Chowdhury, 1970; Jones, A. R., 1978). Glycolysis is inhibited in spermatozoa from treated animals and in spermatozoa from untreated animals exposed to $\alpha$-chlorohydrin in vitro (Brown-Woodman, Mohri, Mohri, Suter \& White, 1978; Ford, Harrison, Takkar \& Waites, 1979). The principal site of inhibition in ram spermatozoa is the glyceraldehyde 3-phosphate dehydrogenase (EC 1.2.1.12) reaction (Brown-Woodman et al., 1978) but this has not been confirmed in a second species. The concentration of ATP in affected spermatozoa falls when they are incubated with glucose (Ford et al., 1979) and they are unable to sustain motility (Coppola, 1969; Brown \& White, 1973). It has been proposed that the inhibition of glycolysis is sufficient to explain the infertility of spermatozoa from treated animals (Brown-Woodman et al., 1978; Ford et al., 1979).

Fructose and glucose are rapidly glycolysed by rhesus monkey ejaculated spermatozoa and can support motility under anaerobic conditions or in the presence of respiratory inhibitors (Hoskins \& Patterson, 1968). The principal product is lactate even under aerobic conditions (Hoskins \& Patterson, 1968; Ford et al., 1979). The mass action ratios of the reactions of the glycolytic pathway indicate that the steps catalysed by hexokinase (EC 2.7.1.1), phosphofructokinase (EC 2.7.1.11) and pyruvate kinase (EC 2.7.1.40) are displaced from equilibrium (Hoskins, Stephens \& Casillas, 1971). Phosphorylation of fructose-6-phosphate limits the rate of 
lactate production in cell-free extracts and phosphofructokinase activity is modulated by the concentrations of the adenine nucleotides and citrate (Hoskins \& Stephens, 1969; Hoskins et al., 1971). This implies that flux through the glycolytic pathway is limited by the activity of phosphofructokinase. However, during the increase in glycolytic flux produced by raising the $\mathrm{pH}$ of intact spermatozoa from 7.4 to $7 \cdot 8$, the control was exerted at glyceraldehyde 3-phosphate dehydrogenase or diphosphoglycerate kinase (EC 2.7.2.3) (Hoskins et al., 1971). Rhesus monkey spermatozoa also have the capacity for active respiration (Hoskins \& Patterson, 1968; Storey, 1978) and can remain motile under aerobic conditions in the absence of a glycolysable substrate.

Opportunities to study primate epididymal spermatozoa are limited so when spermatozoa from the cauda epididymides of rhesus monkeys (which had to be culled for other reasons) were made available by $\mathrm{Dr}$ J. H Marston some of their metabolic characteristics were compared to the properties reported for ejaculated spermatozoa. Since non-human primates are important models in the testing of new contraceptives (Goldzieher, Joshi \& Kraemer, 1974) the effect of $\alpha$-chlorohydrin on glycolysis in rhesus monkey spermatozoa was studied to permit comparison with the non-primate species studied previously.

\section{Materials and Methods}

Three adult rhesus monkeys, Macaca mulatta (body wt $9.95-11.02 \mathrm{~kg}$ ) were sedated with ketamine hydrochloride $(150 \mathrm{mg})$ and anaesthesia was maintained with a mixture of halothane (Fluothane: I.C.I.) and oxygen. The animals were castrated and a plastic cannula placed in the vas deferens. Spermatozoa were then expelled from a cut made in a tubule in the cauda epididymidis by flushing PBS buffer (143 mM-NaCl; $2.7 \mathrm{~mm}-\mathrm{KCl} ; 8.1 \mathrm{~mm}-\mathrm{Na}_{2} \mathrm{HPO}_{4} ; 1.47$ mM- $\mathrm{KH}_{2} \mathrm{PO}_{4} ; 0.8 \mathrm{mM}^{-\mathrm{CaCl}_{2}} ; 0.5 \mathrm{mM}-\mathrm{MgCl}_{2} ; 0.1 \mathrm{~mm}-\mathrm{EDTA} ; 0.1 \%(\mathrm{w} / \mathrm{v})$ bovine serum albumin) down the cannula. Spermatozoa from both epididymides of each monkey were pooled and dispersed in the buffer by gently sucking in and out of a wide-mouthed Pasteur pipette. Incubations were carried out in 10-ml glass conical flasks sealed with caps (Suba-Seal: Gallenkamp) in a shaking water bath at $34^{\circ} \mathrm{C}$. Portions of the suspension $\left(1.2-2.6 \times 10^{8}\right.$ spermatozoa) were incubated for 15 min with $R S$ - $\alpha$-chlorohydrin (Koch-Light, Colnbrook, U.K.) $(0,0.05,1.0,5.0$ or $10.0 \mathrm{~mm})$ in a total volume of $0.8 \mathrm{ml}$. Then $0.2 \mathrm{ml}(1 \mu \mathrm{Ci})$ of $10 \mathrm{mM}-\mathrm{D}-\left[\mathrm{U}-{ }^{14} \mathrm{C}\right]$ glucose was added (Radiochemical Centre, Amersham, U.K.). Incubation was stopped after $1 \mathrm{~h}$ by the addition of $0.5 \mathrm{ml}$ perchloric acid $(10 \%$, w/v). Duplicate control incubations were carried out for each monkey and perchloric acid was added to 2 flasks at the same time as the glucose (zero time).

The ${ }^{14} \mathrm{CO}_{2}$ was drawn off in a stream of air and trapped in hyamine hydroxide $(0.2 \mathrm{M})$ dispersed on glass-fibre filter paper. Radioactivity was measured in a liquid scintillation spectrometer (Nuclear Enterprises, Edinburgh). The sperm suspension was homogenized for 15 sec with an Ultra-turrax blender and centrifuged $\left(600 \mathrm{~g}, 10 \mathrm{~min}, 0-4^{\circ} \mathrm{C}\right)$. The supernatant was decanted, weighed and neutralized to $\mathrm{pH} 6.0$ by adding $2.3 \quad \mathrm{M}-\mathrm{K}_{2} \mathrm{CO}_{3}$ containing 0.7 M-2- $(N$-morpholino) ethane sulphonic acid $(0.2 \mathrm{ml})$; potassium perchlorate was removed by centrifugation $\left(600 \mathrm{~g}, 10 \mathrm{ml}, 0-4^{\circ} \mathrm{C}\right)$ and the supernatant was stored at $-20^{\circ} \mathrm{C}$. Lactate was assayed by the method of Hohorst (1963), adenine nucleotides as described by Williamson \& Corkey (1969) and glycolytic intermediates after Maitra \& Estabrook (1964).

\section{Results}

More glucose was converted to lactate than to $\mathrm{CO}_{2}$ under control conditions (Table 1). The production of both was inhibited by $\alpha$-chlorohydrin $(5$ and $10 \mathrm{mM}$ ) but the effect on lactate was more complete (Table 1). 
Table 1. The effect of $a$-chlorohydrin on the production of $\mathrm{CO}_{2}$ and lactate from $2 \mathrm{~mm}-\mathrm{IU}-{ }^{14} \mathrm{Clglucose}$ by spermatozoa from the cauda epididymidis of rhesus monkeys

\begin{tabular}{|c|c|c|c|c|c|}
\hline & \multicolumn{5}{|c|}{$\alpha$-Chlorohydrin conc. (mM) } \\
\hline & 0 (control) & 0.5 & 1.0 & $5 \cdot 0$ & $10 \cdot 0$ \\
\hline $\begin{array}{l}\left.\text { nmol D-[U- }{ }^{14} \mathrm{C}\right] \text { glucose converted to } \\
{ }^{14} \mathrm{CO}_{2} / 10^{8} \text { spermatozoa } / \mathrm{h}\end{array}$ & $16 \cdot 5 \pm 3 \cdot 4$ & $16 \cdot 6 \pm 4 \cdot 2$ & $18 \cdot 3 \pm 4 \cdot 6$ & $7 \cdot 4 \pm 3 \cdot 3^{*}$ & $1.9 \pm 0.4^{* *}$ \\
\hline $\mathrm{nmol}$ lactate produced $/ 10^{8}$ spermatozoa $/ \mathrm{h}$ & $160 \pm 30$ & $125 \pm 30$ & $95 \pm 57$ & $-15 \pm 14^{* *}$ & $-23 \pm 20^{* *}$ \\
\hline
\end{tabular}

Results are the mean \pm s.e.m. of 3 experiment, each using spermatozoa from a different monkey; duplicate control incubations were done on each occasion. A negative quantity signifies a decrease in concentration during the incubation.

Significantly different from control value: ${ }^{*} P<0.05 ;{ }^{* *} P<0.01$ (one-way analysis of variance).

The concentrations of the adenine nucleotides, the energy charge $\left(\mathrm{ATP}+\frac{1}{2} \mathrm{ADP}\right) /(\mathrm{ATP}+$ ADP + AMP) (Atkinson \& Walton, 1967) and the ATP/ADP ratio did not change during $1 \mathrm{~h}$ incubation with 2 mM-glucose under control conditions (Table 2). In the presence of $\alpha$-chlorohydrin ( 5 or $10 \mathrm{mM}$ ) the energy charge and ATP/ADP ratio were significantly reduced. The total adenine nucleotide content did not change significantly but ATP and ADP were converted into AMP (Table 2).

Table 2. The effect of $\alpha$-chlorohydrin on the concentrations of adenine nucleotides ( $\mathrm{nmol} / 10^{8}$ spermatozoa) in spermatozoa from the cauda epididymidis of the rhesus monkey

\begin{tabular}{|c|c|c|c|c|c|c|}
\hline & \multirow{2}{*}{$\begin{array}{l}\text { Zero } \\
\text { time }\end{array}$} & \multicolumn{5}{|c|}{$\alpha$-Chlorohydrin conc. (mM) } \\
\hline & & 0 (control) & 0.5 & $1 \cdot 0$ & $5 \cdot 0$ & $10 \cdot 0$ \\
\hline ATP & $21 \cdot 2 \pm 8 \cdot 1$ & $19 \cdot 1 \pm 6 \cdot 4$ & $17 \cdot 1 \pm 5 \cdot 3$ & $11 \cdot 6 \pm 8 \cdot 3$ & $2 \cdot 3 \pm 1 \cdot 0^{*}$ & $1.8 \pm 0.6^{*}$ \\
\hline $\mathrm{ADP}$ & $36 \cdot 7 \pm 2 \cdot 9$ & $30.9 \pm 4.2$ & $24 \cdot 5 \pm 6 \cdot 9$ & $27.4 \pm 10.9$ & $13 \cdot 1 \pm 4 \cdot 3^{*}$ & $13 \cdot 4 \pm 3 \cdot 3^{*}$ \\
\hline AMP & $18 \cdot 5 \pm 3 \cdot 2$ & $18 \cdot 2 \pm 5 \cdot 0$ & $11.4 \pm 1.9$ & $32 \cdot 0 \pm 9 \cdot 3$ & $37 \cdot 3 \pm 4 \cdot 4^{*}$ & $39 \cdot 6 \pm 2 \cdot 6^{*}$ \\
\hline $\begin{array}{r}\text { Total adenine } \\
\text { nucleotides }\end{array}$ & $76 \cdot 4 \pm 5 \cdot 7$ & $68 \cdot 2 \pm 5 \cdot 2$ & $52.9 \pm 11.7$ & $71.0 \pm 10 \cdot 0$ & $52 \cdot 7 \pm 3 \cdot 3$ & $54 \cdot 7 \pm 1 \cdot 5$ \\
\hline $\begin{array}{l}\text { Energy charge } \\
\left(\text { ATP + } \frac{1}{2} \text { ADP }\right)\end{array}$ & $0.50 \pm 0.05$ & $0.50 \pm 0.06$ & $0.54 \pm 0.06$ & $0.32 \pm 0.13$ & $0.17 \pm 0.05^{*}$ & $0.15 \pm 0.04^{*}$ \\
\hline$(\mathrm{ATP}+\mathrm{ADP}+\mathrm{AMP})$ & & & & & & \\
\hline
\end{tabular}

ATP/ADP $\quad 0.55 \pm 0.11 \quad 0.60 \pm 0.10 \quad 0.69 \pm 0.04 \quad 0.33 \pm 0.12 \quad 0.16 \pm 0.14^{*} \quad 0.13 \pm 0.04^{*}$

Values are the mean \pm s.e.m. of 3 experiments, each using spermatozoa from a different monkey. The zero time data are from control incubations acidified immediately before the addition of glucose.

Significantly different from control value: ${ }^{*} P<0.05 ;{ }^{* *} P<0.01$ (one-way analysis of variance).

The concentration of all the glycolytic intermediates measured was low at the end of the 15 min preincubation period (Table 3). The concentration of glucose 6-phosphate, fructose 1,6-bisphosphate and lactate were significantly higher after $1 \mathrm{~h}$ incubation with $2 \mathrm{~mm}$-glucose but triose phosphate, glycerate 3-phosphate and pyruvate changed only slightly (Table 3 ). The presence of $R S$ - $\alpha$-chlorohydrin ( 5 or $10 \mathrm{~mm}$ ) caused a dramatic increase in fructose 1,6-bisphosphate compared to controls. There was a large decrease in the amount of lactate and a small but significant reduction in the glucose 6-phosphate concentration. No change in the concentrations of glycerate 3-phosphate or pyruvate occurred (Table 3). Glycerate 2-phosphate and phosphoenol pyruvate concentrations were too low to measure $\left(<0.2 \mathrm{nmol} / 10^{8}\right.$ spermatozoa) under all the conditions studied. 
Spermatozoa from the cauda epididymidis of a fourth rhesus monkey had an endogenous oxygen uptake of $0.5 \mu \mathrm{mol} / 10^{8} \mathrm{spermatozoa} / \mathrm{h}$ which was increased to about twice that value by $5 \mathrm{~mm}$-lactate or $5 \mathrm{~mm}$-pyruvate or $5 \mathrm{~mm}$-succinate or $5 \mathrm{~mm}$-glycerol 3-phosphate. Oxygen uptake was stimulated by a further $50 \%$ by $10^{-7} \mathrm{M}$-carbonyl cyanide $\mathrm{m}$-chlorophenyl hydrazone or by $6.7 \mathrm{~mm}$-caffeine, but $5 \mathrm{~mm}$-glucose or $5 \mathrm{~mm}$-citrate had no significant effect.

Table 3. The effect of addition of glucose and various concentrations of $\alpha$-chlorohydrin on the concentration of glycolytic intermediates in spermatozoa from the cauda epididymidis of rhesus monkey

\begin{tabular}{|c|c|c|c|c|c|c|}
\hline \multirow{2}{*}{$\begin{array}{c}\text { Intermediate } \\
\left(\mathrm{nmol} / 10^{8}\right. \\
\text { spermatozoa) }\end{array}$} & \multirow{2}{*}{$\begin{array}{l}\text { Zero } \\
\text { time }\end{array}$} & \multicolumn{5}{|c|}{$\alpha$-Chlorohydrin conc. (mM) } \\
\hline & & 0 (control) & 0.5 & $1 \cdot 0$ & $5 \cdot 0$ & 10.0 \\
\hline Glucose 6-phosphate & $0.15 \pm 0.10$ & $4.0 \pm 0.40 \dagger$ & $3 \cdot 5 \pm 0 \cdot 30$ & $4 \cdot 1 \pm 1 \cdot 1$ & $1.9 \pm 0.3$ & $1.7 \pm 0.5$ \\
\hline $\begin{array}{l}\text { Fructose 1,6-bis- } \\
\text { phosphate }\end{array}$ & $0.26 \pm 0.14$ & $3.2 \pm 0.9 \dagger$ & ND & ND & $30 \cdot 8 \pm 6 \cdot 6^{* *}$ & $37 \cdot 8 \pm 3 \cdot 7^{* *}$ \\
\hline Triose phosphate $\S$ & $1 \cdot 14 \pm 0.44$ & $1.75 \pm 0.58$ & ND & ND & $3 \cdot 1 \pm 0.41$ & $2.5 \pm 0.29$ \\
\hline Glycerate 3-phosphate & $0.37 \pm 0.15$ & $0.11 \pm 0.06$ & ND & ND & $0.03 \pm 0.05$ & $0 \cdot 16 \pm 0.09$ \\
\hline Pyruvate & $0.18 \pm 0.10$ & $0.60 \pm 0.28$ & ND & ND & $0.19 \pm 0.33$ & $0.45 \pm 0.36$ \\
\hline Lactate & $23 \pm 19$ & $180 \pm 25 \ddagger$ & $150 \pm 30$ & $118 \pm 55$ & $8 \pm 6^{* *}$ & $0 \pm 0^{* *}$ \\
\hline
\end{tabular}

Values are mean \pm s.e.m. for 3 experiments, each using spermatozoa from 3 monkeys. ND, not determined.

Significantly different from zero time value: $† P<0.05 ; \ddagger P<0.01$ ( $t$ test).

Significantly different from control value: ${ }^{* *} P<0.01$ (one-way analysis of variance).

$\S$ Dihydroxyacetone phosphate + glyceraldehyde 3-phosphate.

\section{Discussion}

The rates of $\mathrm{CO}_{2}$ and lactate production from $2 \mathrm{~mm}$-glucose observed in this experiment were similar to the rates of production from $11 \mathrm{mM}$-fructose reported for ejaculated spermatozoa of rhesus monkeys (Hoskins \& Patterson, 1968). This is in accordance with the observation that either concentration of sugar would be sufficient to support maximal glycolysis by human ejaculated spermatozoa (Peterson \& Freund, 1969). The observations on the respiration of the epididymal spermatozoa are also similar to the results obtained with ejaculated spermatozoa (Hoskins \& Patterson, 1968).

Although the spermatozoa remained active after incubation the energy charge and the ATP/ADP ratio were low compared to those in most viable systems (Chapman, Fall \& Atkinson, 1971), including human ejaculated spermatozoa (Chulavatnatol \& Haesungcharern, 1977) and bovine epididymal spermatozoa (Hoskins, Munsterman \& Hall, 1975; Cascieri, Amann \& Hammerstedt, 1976). However, the energy charge was identical to that found in monkey ejaculated spermatozoa (Hoskins et al., 1971) and similar to that observed in rat epididymal spermatozoa after incubation with glucose for $10 \mathrm{~min}$ (Ford \& Waites, 1978).

The concentration of glycolysable sugar is low in the cauda epididymidis (see Jones, R., 1978; Cooper \& Waites, 1979) but spermatozoa are mixed with a high concentration of fructose during ejaculation. The present experiment is a model of this event. The low energy charge in the spermatozoa should ensure that phosphofructokinase is fully activated (Hoskins \& Stephens, 1969) and the changes in the glycolytic intermediates suggest that the activity of glyceraldehyde 3-phosphate dehydrogenase limits flux through the pathway. Control at this site also occurs in rat heart under conditions in which phosphofructokinase is activated (Williamson, 1965; Rovetto, Neely \& Whitmer, 1974). 
Glyceraldehyde 3-phosphate dehydrogenase is a potential control enzyme in other tissues (Clark \& Lardy, 1976) and it was the apparent regulatory site in rhesus monkey ejaculated spermatozoa subjected to $\mathrm{pH}$ changes which altered their glycolytic flux (Hoskins \& Stephens, 1969). Changes in the activity of glyceraldehyde 3-phosphate dehydrogenase may be responsible for the alterations in the glycolytic capacity of bovine spermatozoa during maturation (Hoskins et al., 1975). In the present experiments other control mechanisms must exist to prevent excessive accumulation of the early intermediates of the pathway, e.g. inhibition of hexokinase by glucose 6-phosphate (see Walker, 1966).

The differences observed in the concentrations of glycolytic intermediates in the spermatozoa in the presence of 5 or $10 \mathrm{mM}-\alpha$-chlorohydrin suggest that the pathway is inhibited at the glyceraldehyde 3-phosphate dehydrogenase reaction. This is the same site as in ram spermatozoa (Brown-Woodman et al., 1978). The small increase in triose phosphate reflects the equilibrium of the aldolase reaction which favours the production of fructose 1,6-bisphosphate (Rutter, 1961). Technical factors make it very difficult to demonstrate a decrease in metabolites present in very low concentrations such as glycerate 3-phosphate and pyruvate. However, it is clear that their concentrations do not increase as they would be expected to do if any enzyme further down the pathway were inhibited. The antifertility action of $\alpha$-chlorohydrin is associated with inhibition of glycolysis in the spermatozoa of the species studied so far (Ford et al., 1979). However, high doses of $\alpha$-chlorohydrin are required to inhibit the oxidation of acetate, pyruvate or lactate by ram spermatozoa (Brown-Woodman et al., 1978). Moreover, spermatozoa from rats treated with 6-chloro-6-deoxyglucose $(24 \mathrm{mg} / \mathrm{kg} /$ day $)$, which has an antifertility effect similar to that of $\alpha$-chlorohydrin (Ford \& Waites, 1978), can remain motile and retain a high energy charge when supplied with $2 \mathrm{~mm}$-pyruvate plus $4 \mathrm{~mm}$-DL-lactate as substrates although these parameters decline rapidly when $2 \mathrm{mM}$-glucose is the only substrate given (Ford \& Waites, 1980). Therefore, unless spermatozoa are compelled to metabolize sugar at some stage, e.g. whilst trapped in the mass of seminal plasma (Mann, 1967), they could obtain sufficient energy from other sources and although the inhibition of glycolysis by $\alpha$-chlorohydrin is a striking and consistent effect it might not be sufficient to explain the infertility of the spermatozoa.

We thank Dr J. H. Marston, Department of Anatomy, University of Birmingham, who provided the monkeys and performed the surgical work, and Professor G. M. H. Waites for helpful discussion. The work was supported by Grant No. 75311 from the World Health Organization.

\section{References}

Atkinson, D.E. \& Walton, G.M. (1967) Adenosine triphosphate conservation in metabolic regulation. $J$. biol. Chem. 242, 3239-3241.

Brown, P.D.C. \& White, I.G. (1973) Studies on the male anti-fertility drug 3-chloro-1,2-propandiol. J. Reprod. Fert. 32, 337-338.

Brown-Woodman, P.D.C., Mohri, H., Mohri, T., Suter, D. \& White, I.G. (1978) Mode of action of $\alpha$-chlorohydrin as an antifertility agent. Biochem. $J$. 170, 23-27.

Cascieri, M., Amann, R.P. \& Hammerstedt, R.H. (1976) Adenine nucleotide changes at the initiation of bull sperm motility. J. biol. Chem. 251, 787-793.

Chapman, A.G., Fall, L. \& Atkinson, D.E. (1971) Adenylate energy charge in Escherichia coli during growth and starvation. J. Bacteriol. 108, 10721086.

Chulavatnatol, M. \& Haesungcharern, A. (1977)
Stabilization of adenylate energy charge and its relation to human sperm motility. J. biol. Chem. 252, 8088-8091.

Clark, M.G. \& Lardy, H.A. (1976) Regulation of intermediary carbohydrate metabolism. In $M T P$ International Review of Science, Biochemistry Series 1, Biochemistry of Carbohydrates, Vol. 5, pp. 223-266. Eds H. L. Kornberg \& D. C. Philips. Butterworths, London.

Coppola, J.A. (1969) An extra-gonadal male fertility agent. Life Sciences 8, 43-48.

Cooper, T.G. \& Waites, G.M.H. (1979) Investigation by luminal perfusion of the transfer of compounds into the epididymis of the anaesthetized rat. J. Reprod. Fert. 56, 159-164.

Ford, W.C.L. \& Waites, G.M.H. (1980) The control of male fertility by 6-chloro-6-deoxysugars. Reprod.

Nutr. Dével. 20 (in press).
Downloaded from Bloscientifica.com at $04 / 26 / 2023$ 08:46:24AM 
Ford, W.C.L. \& Waites, G.M.H. (1978) Chlorinated sugars: a biochemical approach to the control of male fertility. Int. J. Androl., Suppl. 2, 541-564.

Ford, W.C.L., Harrison, A., Takkar, G.L. \& Waites, G.M.H. (1979) Inhibition of glucose catabolism in rat, hamster, rhesus monkey and human spermatozoa by $\alpha$-chlorohydrin. Int. J. Androl. 2, 275-288.

Goldzieher, J.W., Joshi, S. \& Kraemer, D.C. (1974) Non-human primates in contraceptive research. In Pharmacological Models in Contraceptive Development, pp. 90-118. Eds M. H. Briggs \& E. Diczfalusy. WHO, Geneva.

Hohorst, H.J. (1963) L(+)-Lactate. In Methods of Enzymatic Analysis, Vol. II, pp. 266-270. Ed. H. U. Bergemeyer. Verlag Chemie, Weinheim.

Hoskins, D.D. \& Patterson, D.L. (1968) Metabolism of rhesus monkey spermatozoa. J. Reprod. Fert. 16, 183-195.

Hoskins, D.D. \& Stephens, D.T. (1969) Regulatory properties of primate sperm phosphofructokinase. Biochim. Biophys. Acta 191, 292-302.

Hoskins, D.D., Stephens, D.T. \& Casillas, E.R. (1971) Enzymic control of fructolysis in primate spermatozoa. Biochim. Biophys. Acta 237, 227-238.

Hoskins, D.D., Munsterman, D. \& Hall, M.L. (1975) The control of bovine sperm glycolysis during epididymal transit. Biol. Reprod. 12, 566-572.

Jones, A.R. (1978) The antifertility actions of $\alpha$ chlorohydrin in the male. Life Sciences 23, 16251646.

Jones, R. (1978) Comparative biochemistry of mammalian epididymal plasma. Comp. Biochem. Physiol. 61B, 365-370.

Kirton, K.T., Ericsson, R.J., Ray, J.A. \& Forbes, A.D. (1970) Male antifertility compounds. Efficacy of U-5897 in primates (Macaca mulatta). J. Reprod. Fert. 21, 275-278.
Maitra, P.K. \& Estabrook, R.W. (1964) Fluorimetric analysis of glycolytic intermediates. Analyt. Biochem. 7, 472-484.

Mann, T. (1967) Sperm metabolism. In Fertilization, Vol. 1, pp. 99-116. Eds C. B. Metz \& A. Monroy. Academic Press, New York.

Peterson, R.N. \& Freund, M. (1969) Glycolysis by washed suspensions of human spermatozoa. Effect of substrate, substrate concentration and changes in medium composition on the rate of glycolysis. Biol. Reprod. 1, 238-246.

Rovetto, M.J., Neely, J.R. \& Whitmer, J.T. (1974) The relationship between glycolytic flux and coronary flow in isolated rat hearts. Fedn Proc. Fedn Am. Socs exp. Biol. 33, 363.

Rutter, W.J. (1961) Aldolase. In The Enzymes, Vol. 5, pp. 341-366. Eds P. D. Boyer, H. Lardy \& K. Myrback. Academic Press, New York.

Setty, B.S., Kar, A.B., Roy, S.K. \& Chowdhury, S.R. (1970) Studies with sub-toxic doses of $\alpha$-chlorohydrin in the male monkey (Macaca mulatta). Contraception 1, 279-289.

Storey, B.T. (1978) Effect of ionophores, inhibitors and uncouplers of oxidative phosphorylation on sperm respiration. Arch. Androl. 1, 169-178.

Walker, D.G. (1966) The nature and function of hexokinases in animal tissue. Essays in Biochemistry 2,33-67.

Williamson, J.R. (1965) Metabolic control in the perfused rat heart. In Control of Energy Metabolism, pp. 333-346. Eds B. Chance, R. W. Estabrook \& J. R. Williamson. Academic Press, New York.

Williamson, J.R. \& Corkey, B.A. (1969) Assays of intermediates of the citric acid cycle and related compounds by fluorimetric enzyme methods. In Methods of Enzymology, Vol. 13, pp. 434-513. Ed. J. M. Lowenstein. Academic Press, New York.

Received 9 November 1979 